\title{
Curriculum Development and Research on Construction Safety Psychology and Behavior
}

\author{
Pei $\mathrm{Wu}$ \\ School of Architectural Engineering \\ Chongqing University of Science and Technology \\ Chongqing, China \\ 555wp555@163.com
}

\author{
Xiao Dang \\ School of Architectural Engineering \\ Chongqing University of Science and Technology \\ Chongqing, China \\ 353803733@qq.com
}

\begin{abstract}
The purpose of the developing on this course is to improve college students' ability on psychological cognition and behavioral cultivation of construction safety on the basis of mastering the basic skills in the construction operation and management methods. The research methods of this paper include consulting relevant domestic and foreign literature, summaries, field interviews and surveys. This paper analyzes the necessity of the development of Construction Safety Psychology and Behavior research, development idea, orientation, goal and content, in order to improve the teaching level and safety level of the construction industry, to cultivate qualified, excellent and professional construction talents adapting to the development of modern society.
\end{abstract}

Keywords-construction industry; safety psychology; behavior training; curriculum development

\section{INTRODUCTION}

In recent years, China's construction industry safety accidents occur frequently. The number of accidents and casualties are significantly higher than other industries. The construction industry has become one of the most dangerous industries in our country's[1]. Workers in construction industry work in a very unfavorable environment with high risk and overload of work. Meanwhile, they suffer from nutritional deficiency and have to do very complicated and demanding work at height and outdoors. As the most active factors and core factors, there is an inevitable relationship between the worker's safety behavior and safety accidents. Statistics of construction accidents at domestic and abroad show that the human has been a vital factor in construction accidents and unsafe events all the time, accounting for more than $80 \%$ of the accident causes [2]. The psychological characteristics and mental health factors of human are the most important components of human factors. The psychological characteristics, mental health and the construction safety performance level of construction practitioners are closely related.

"Safety Psychology" is a scientific research on the safety psychology and safety behavior of employees, according to the relationship among operators, machines, equipment, materials, methods, skills, working environment and so on in the process of production[3-4]. By its definition, the research and application of "safety Psychology" is crucial to improve the safety of the production process. It is because of the importance of the operator's psychology to the safety of the construction operation, most of the architectural colleges and universities at home and abroad have set up the relevant courses of construction safety psychology. Typical psychology courses related to safety included "Safety Psychology and Behavior Training" [5], "Safety Psychology" [6-7], "Safety Psychology and Behavior Management" [8] and "Safety Management" [9] and so on. However, in the education of architectural universities and colleges in China, the course of safety psychology with architectural characteristics is in the blank at present. Therefore, we have developed and studied the curriculum of Construction Safety Psychology and Behavior.

\section{COURSE CONNOTATION OF CONSTRUCTION SAFETY PSYCHOLOGY AND BEHAVIOR}

Safety psychology consists of two perspectives: safety basic psychology and safety applied psychology. Safety applied psychology focuses on the application of the basic principles of psychology in various practical fields, Construction Safety Psychology and Behavior is the branch of safety applied psychology. Construction Safety Psychology and Behavior is different from the general category of applied psychology. On the one hand, it emphasizes the application of the psychological theory and method in the field of construction to solve some practical problems in construction and management; on the other hand, it also involves the construction industry safety production problems. Therefore, the connotation of Construction Safety Psychology and Behavior is to study psychological characteristics and behavior tendency of unsafely accidents caused by "human" in the key positions in the production and operational process in construction industry and propose corresponding and targeted measurements for improvement and management. The Construction's entire life cycle involves the design, construction, use, maintenance, scrap and other aspects, which involves the key steps affecting the construction safety operation including design stage, construction stage and maintenance stage. People in each key position are closely related to safety factors, in the entire construction industries, the psychology of people is not only the strongest 
strain capacity, the most flexible factors, but also the most stable, the most easily interfered by other factors and the most difficult to be standardized factors [5]. So to speak, the psychological factors of people run through the whole life cycle of construction. The unsafe accidents and events caused by psychological factors of people are common.

\section{NECESSITY OF CURRICUlUM DEVELOPMENT OF CONSTRUCTION SAFETY PSYCHOLOGY AND BEHAVIOR}

The safety use of the building cannot do without to learn and research psychological laws of people in the key positions. Only to research and understand clearly and deeply the perception, attention, information processing and decision-making of the design staff, construction personnel, management personnel and other working groups can enhance the self-psychological consciousness of construction practitioners and cultivate qualified construction practitioners in order to prevent accidents from happening in the future's daily work. There are two practical necessities to open this course: (1) to cultivate students' good sense of safety production. After graduation from architectural colleges, about $80 \%$ of architecture graduates enter the construction industry and become designers, construction personnel, technical personnel, special operations personnel and management personnel. It can be said that their work behavior directly affects the safety level of China's construction industry in the future. In the student stages, there graduates are whether to master the basic knowledge of safety psychology, whether to establish the basic sense of safety production, which are significant for them to develop good habits of safety behavior in their future jobs. The course is a science which the construction personnel can generate the safety psychology and safety behavior in the construction process, according to the relationship among operating personnel, equipment, material, method, operating environment, to provide the basic platform which students could understand themselves, understand this industry, understand construction safety psychological activities in all aspects in an accurate manner. (2) to shape the students' mental quality of health and safety. The study of this course, in addition to improve the universal application and understanding of construction safety psychology and behavior, enhance the basic research ability of construction safety psychology, but also to establish the scientific spirit and the exercise attitude of seeking truth from facts, thus to form rigorous and careful logical thinking habits. For example, through analyzing the domestic and foreign construction safety production features and man-made accident cases, psychological hidden troubles in the working environment of high intensity and pressure can be sorted out, which can enable students to understand the influence of personal emotion and the emotion psychology to construction safety, to understand the relationship between personality and construction safety and grasp the psychological factors that lead to human error, thus helping students shape and maintain safe and healthy psychological quality in the construction key positions of the future.

\section{Thoughts on CuRriCulum DEVELOPMENT OF BuILDING SAFETY PSYCHOLOGY AND BEHAVIOR}

\section{A. Scientific Design System and Content Combined with Professional Construction Requirements}

According to the orientation, conditions of school operation, talents training requirements of construction engineering college and local economic development, construction safety psychology and behavior theory teaching characterized by the organic combination of basic disciplinary knowledge and the scope of disciplinary knowledge are emphasized, improving students' practical ability is set up as the goal and teaching module featuring the hierarchy and coordinate of courses is focused on.

\section{B. Reform Traditional Teaching Methods and Explore New Teaching Mode}

The traditional teaching mode is mainly based on the teaching of teachers. The amount of teaching information is limited and students can not feel the fun of learning in the traditional teaching mode. The traditional teaching mode is improved into such mode as is carried out by using multimedia and blackboard-writing. According to the course characteristics of construction safety psychology and behavior, the past general and tedious knowledge teaching can be displayed directly and vividly contents through graphics, animation, video and other forms, which can cultivate and strengthen students' interest in learning and enrich and expand the teaching information of Construction Safety Psychology and Behavior.

\section{Building auxiliary teaching website and setting up extracurricular learning platform}

In order to facilitate students' learning after class and improve comprehensively the quality of teaching, this project will build Construction Safety Psychology and Behavior course learning website based on the campus network. The website with the basic content of Construction Safety Psychology and Behavior courses, which covers video, micro class, teaching resources, exercise resources and related web resources (Table I) can not only enrich the students' classroom learning content, but also help students to choose the way of learning in accordance with their own habits and hobbies. At the same time, the system can timely update, supply new learning materials and be accompanied by a large number of engineering accident pictures, cartoon and video, effectively strengthen the students' professional awareness and engineering awareness. The system is significant to cultivate students' self-learning ability, enrich students' learning content and improve the teaching quality of the course. 
TABLE I. CURRICULUM DEVELOPMENT RESULTS OF BUILDING SAFETY PSYCHOLOGY AND BEHAVIOR

\begin{tabular}{|c|c|}
\hline Micro class & Add 2 sections \\
\hline Paper bank & Add 10 sets \\
\hline Course material & $\begin{array}{c}\text { The program was selected into applied } \\
\text { professional teaching materials }\end{array}$ \\
\hline Exercise database & $\begin{array}{c}100 \text { choice questions, 20 questions and answers, } \\
10 \text { calculation questions }\end{array}$ \\
\hline Engineering case base & Add 1 case \\
\hline $\begin{array}{c}\text { Psychological } \\
\text { experiment }\end{array}$ & Add 2 psychological experiments \\
\hline \multicolumn{2}{|c|}{$\begin{array}{c}\text { The whole process safety implementation process of a standardized safety } \\
\text { production system }\end{array}$} \\
\hline
\end{tabular}

\section{ANALysis of CURRICUlum DESIGN ELEMENTS OF BUILDING SAFETY PSYCHOLOGY AND BEHAVIOR}

\section{A. Curriculum Orientation}

In order to better realize the teaching effect, it is suggested that the students should learn the basic knowledge of psychology and master the course of advanced mathematics. Because the study of this course is conducive to master other professional learning, therefore, this course can be designed as a public compulsory professional basic course for construction students. The time for studying this course can be set up in the second semester of the second grade of the university. In the selecting course, students will not be limited by their own major and be encouraged to choose courses of other majors, which, on the one hand, can cultivate students' innovative ability by studying interdisciplinary knowledge; on the other hand, is conducive to form chain thinking for construction safety production.

\section{B. Curriculum Objectives}

Through the study of this course, the students are familiar with and master basic theory, basic knowledge and basic skills of the Construction Safety Psychology and Behavior, understand the current development of domestic and international construction safety psychology and behavior, get familiar with unsafe accidents caused by psychology at home and abroad construction safety production process, master the analysis method of this kind of incidents, learn to understand the interdependence of "human - machine - material - method - environment" on whole and safeguard mental health of construction personnel, management personnel and technical personnel from the perspective of the requirements of psychological quality imposed on practitioners due to special occupation, which can ensure the importance of construction safety and lay the foundation for the safer construction industry.

\section{Curriculum Contents}

Curriculum content refers to the unique principles, views, problems and ways of dealing with problems in various disciplines. In order to conform to the basic tasks of the school, on the one hand, we should consider the correlation with the curriculum objectives; on the other hand, we should consider the validity and scientificity of the curriculum content in choosing, determining and arranging the course content.
By adopting the modularized method, the teaching content of this course aims at psychological application by different practitioner in different stages and designs different modules including design, construction, management, etc. The major sever modules are as follows:

(1)Construction safety psychology and behavior basic knowledge module. This module mainly includes overview of construction safety psychology and behavioral cultivation, the basic knowledge of psychology, the emergence and development of safety psychology, research methods, research contents and research objects of safety psychology, the application of safety psychology in construction and life.

(2) Psychological process and safety of construction workers. This module mainly elaborates the psychological process and security of construction practitioners from three aspects: cognitive process, emotional process and will process. Cognitive process includes feeling, perception, attention, memory, thinking, which is such psychological phenomenon as presents the characteristic of progressively rising; emotional process is the one which can generate the experience, emotion, feelings and sentiment of attitude when understanding these matters; volitional action process includes the confirmation of the aims of actions and formulation of the plan of actions, two stages in which actions are taken to ensure to achieve such aims and two stages in which actions are taken and decisions are carried out enclosed with 20 questions on willpower level.

(3) Personality, psychology and safety of construction workers. Personality is an important factor that affects the behavior of construction workers. Personality psychology has the frequent and stable characteristics, and it is affected by genetic factors, environmental factors, social factors, accidental factors and other factors. Personality psychology includes temperament, character and ability. Fifth Century BC in ancient Greek doctor Hippocrates believes that the human body has four kinds of blood, blood, phlegm, yellow bile, black bile, according to the proportion of four kinds of blood in the body for different types of people, the temperament is divided into four types, namely, sanguine, choleric, phlegmatic melancholic; the plex personality characteristics including; cognitive characteristics and emotional characteristics, will feature and attitude characteristics; ability refers to the psychological characteristics of personality which can successfully complete an activity with the ability of the formation include: genetic factors, environmental factors, practice and personality.

(4) Group behavior and safety of construction workers. Effect of learning and mastering individual behavior, interpersonal relationship, group cohesion, group norms of individual psychology and behavior including the knowledge of this module, better play the role of the group, to ensure that the process of group work in the operation of construction personnel life and production safety etc.. 
(5) Management behavior and safety of construction workers. At present, most of the contents of safety management focus on the extreme harm caused by safety production, and restrict and motivate people's behavior in the form of system, which does not fundamentally solve the problem of people's understanding and pursuit of safety. In order to realize the true meaning of safety management, it is necessary to implement a feasible incentive mechanism, and incentive is the core issue of management. In the process of safety management, everyone needs motivation, including self-encouragement, leadership incentives, and colleagues incentives. In order to improve the safety management, we should not only use the incentive mode reasonably, but also grasp and use the relationship and law of leadership psychology and safety behavior effectively. The leader is the core of the organization, and the operation of the organization is carried out around the leader. The function of the leader is mainly embodied in three aspects in the safety management: safety decision-making, organization coordination and motivation. Besides the establishment of efficient management system, this module is the implementation of enterprise safety management to help each member of enterprises to establish a good living environment.

(6) The construction workers' individual behavior and safety. Human's individual behavior includes life behavior and homework behavior. The main causes of individual behavior differences include genetic factors, environmental factors, psychological factors and physiological factors. This module studies the human behavior, summarizes the behavior rule, and forecasts the human behavior, thus carrying out efficient intervention and control for unsafe behavior. The unsafe behavior is the result of many factors. Reduction of unsafe behavior and control should start with safe system of man- machine- material- environment management, including the following three steps: the use of personnel selection, equipment design and improvement of the working environment and safety management science.

(7)Mental health and safety of construction workers. This module mainly focuses on the psychological health problems of people; the cause of mental health problems including social factors, business factors, personal; including the debugging method, in the mental health problems of language regulation, divert attention, catharsis, dialectical thinking, roles, psychological counseling; health problems of the improvement measures; physiological principle of psychology and behavior regulation of people, namely reason when people pleasure, excitement and impulse response is the psychological and behavioral regulation of nerve stimulation substances secreted, and bring out a series of actions, these substances will be followed by -ATP dopamine system, emotional brain the nerve muscle system chain, and anti-social brain regions, the prefrontal will power 7 systems; and that the mental health foundation diet The food and the role of principle help to cultivate a good mood, which can include: stable food, can suppress the anger of food, can improve the mood levels of food, can improve the symptoms of anxiety, paranoid mood food can turn the food, can help people overcome laziness, mental retardation, emotional irritability, inattention the food. The impact of nutrition level of people on security is stated.

\section{CONCLUSION}

Based on accurate positioning and relying on newlydeveloped idea, this course with clear tasks as the carrier makes students get familiar with and master the basic theories, knowledge and skills of construction safety psychology and behavior, cultivates their sound safe production awareness and shapes psychological quality of safety and health for them. The purpose of this course is to improve the teaching level and safety level of the construction industry and cultivate qualified, excellent and professional construction talents adapting to the development of modern society.

\section{REFERENCES}

[1] Pei Wu, Long Chen, Zili Zhao. Discussion on the safety management and implementation of the whole process of construction engineering [J] industrial safety and environmental protection, 2016,42 (4):97-100. (In Chinese)

[2] Chunquan Li. The role of psychology in building safety production [J]. Shanxi construction industry.2012 (11): 41-43.(In Chinese)

[3] Harris,D.The influence of human factors on operational effi-ciency [J]. Aircraft Engineering and Aerospace Technology, 2006,78(1):20-25.

[4] Jizu Li. Safety psychology [M]. Chinese labour and Social Security Publishing House, 2007. (In Chinese)

[5] Harris,D.The influence of human factors on operational effi-ciency [J]. Aircraft Engineering and Aerospace Technology, 2006,78(1):20-25.

[6] Pei Wu. Yijun Liu. Shanshan Wu. Long Chen. Jianghua Peng. Safety psychology and behavior training [M]. Wuhan: Huazhong University of Science and Technology press, 2016.(In Chinese)

[7] Linke Zheng, Nailu Zhang. Safety psychology [M]. Xi'an Electronic and Science University press, 2014. (In Chinese)

[8] Hui Shao, Qingxian Zhao. Li Ge. Safety psychology and behavior management [M]. Beijing: Chemical Industry Press, 2011.(In Chinese)

[9] Shuicheng Tian, Guoxun King. Safety management [M]. Beijing: chemical mechanical press, 2009.(In Chinese) 